\title{
A NEW DEVICE FOR FASTENING THE CONDOM SHEATH
}

\author{
By M. E. Brooks, M.D. ${ }^{1}$ and R. Spector, ${ }^{2}$ R.N.
}

${ }^{1}$ Sir Ludwig Guttmann Spinal Cord Injury Center, Chaim Sheba Medical Center; ${ }^{2}$ Sackler School of Medicine, Tel Aviv University, Department of Rehabilitation Medicine, Tel Hashomer, Israel

Key Words: Condom sheath; Urinary drainage; Spinal paralysis.

Abstract. A simple device for fastening the condom sheath to the penis is described.

THE methods for securing the condom sheath of the urinary drainage apparatus to the penis include tape, adhesives, rubber bands, etc. These methods are cumbersome and are not conducive to rapid and easy application and removal. They cause penile irritation both along the shaft and on the glans through rubbing

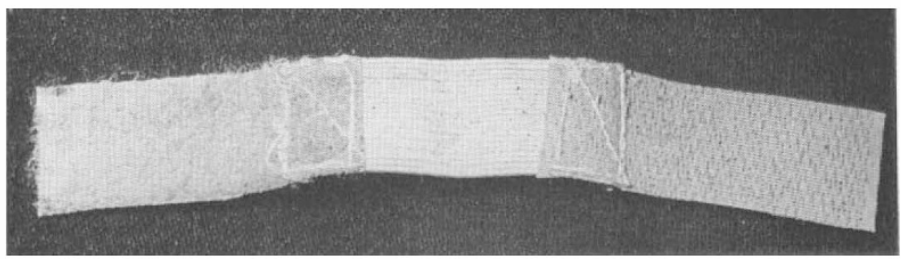

FIG. I

The easily constructed fastener.

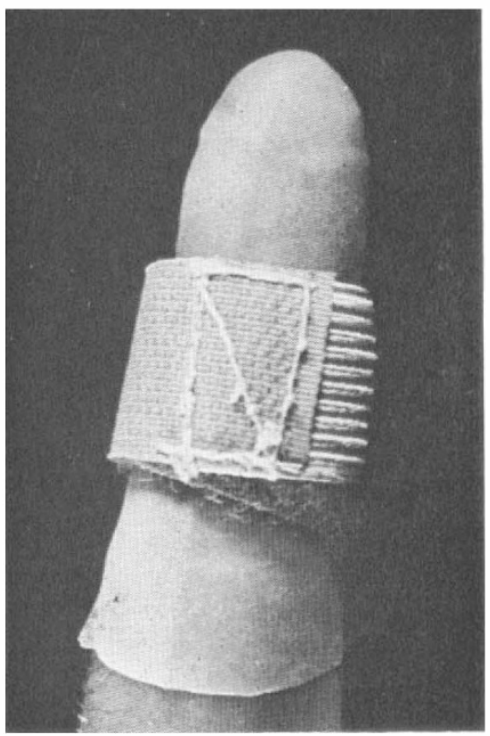

FIG. 2

The fastener in an analogous situation securing a finger cot to a finger. 
or constriction. They do not allow for circumferential changes in the penis during reflex erection. Below we describe a simple device which overcomes many of these problems.

Figure I shows this easily-constructed fastener which can be fabricated in any occupational therapy department or at home by anyone with access to a sewing machine. The fastener consists of a $5 \mathrm{~cm}$ long and $2 \mathrm{~cm}$ wide strip of elastic with velcro closure strips of the same dimensions sewn to each end. The length can be varied depending upon penile size or presence of penile prosthesis. Figure 2 shows this fastener in an analogous situation securing a finger cot to a finger.

Application and removal can be accomplished in quadriplegic patients using flexor hinge splints with appropriate grasping loops attached to the fastener. The device is washable and dries overnight thus facilitating re-use. In the romonth period that patients in our centre have been using this fastener no penile lesions attributed to condom attachment or removal have occurred. Also patients report an increased duration of daily condom use.

\section{RÉSUME}

Un simple exemple pour renfermer le condom drap est décrit et son application démontrée.

\section{ZUSAMMENFASSUNG}

Hiermit wird eine einfache Vorrichtung zur Kondombefestigung und ihre Anwendung beschrieben. 